\title{
Assessment of climate change impacts on agriculture in Mali
}

\author{
Tiémoko Soumaoro
}

Doctoral student at the UFR of Economics and Management of the University Gaston Berger of Saint-Louis, Senegal

\begin{abstract}
:
This study examined the total, direct and indirect effects of climatic variables (temperature and precipitation) on crop yields (maize and millet) between regions located in close proximity to each other a spatial panel analysis of five administrative regions of Mali over a period of 30 years (1988-2017). Our results show that temperature and rainfall have direct, indirect and total effects on maize yield, while the direct effect on millet yield is not statistically significant. In other words, the effect on regions closely linked to region $i$ where the change in temperature or rainfall occurred will be greater than the effect on more remote regions. In addition, the coefficient of variation of precipitation and the interaction between temperature and precipitation as well as area planted all have negative impacts on maize yield. However, millet yield is negatively correlated with drought in the study area. Based on these findings, decisionmakers need to take into account that conditions in surrounding areas can influence cereal crop yields and that spillover effects differ between crop types. Investments in agricultural research and development must be encouraged to counter the effects of climate change.
\end{abstract}

Key words: climate change, food crops, Mali, spatial panel

\section{Introduction}

The recent warming of the global average temperature has led to renewed interest in this study. These studies are often carried out on a large scale. And, according to the Intergovernmental Panel on Climate Change, the global average temperature at the earth's surface increased by about $0.8^{\circ} \mathrm{C}$ between 1880 and 2012 (IPCC, 2013). This global warming would exceed $2^{\circ} \mathrm{C}$ on average at the end of the $21^{\text {th}}$ century compared to the reference period 1850-1900. More likely increases are still expected in many parts of the world according to IPCC simulation models. On the other hand, assessing the trend for rainfall is more complex because of the considerable variations between and within countries. Indeed, overall rainfall has tended to decline at least since the 1950s. In particular, West Africa and the tropical rainforest areas have experienced greater variability in rainfall and a resurgence of more intense and widespread droughts (IPCC, 2013).

In recent studies in West Africa, Roudier (2012) uses the M.S.C. approach with the Sarra-H model to assess the impact of climate change on three contrasting varieties of millet and three varieties of sorghum in West Africa. The author finds a "negative evolution of average yield mainly due to the increase in temperatures that rainfall can only mitigate or aggravate". He also finds that this impact is "more negative for short-cycle, constant-cycle varieties than for photoperiod-sensitive varieties". NELSON and al (2009), in their studies of the impact of climate change on agriculture and the costs of adaptation. The results of their studies show that agriculture and human well-being will be negatively affected by climate change. In addition, crop yields will decrease, production will be affected, crop and meat prices will increase and cereal consumption will decline, leading to a reduction in calorie intake and an increase in child malnutrition.

For several decades, Mali, like other countries in the West African region, has been experiencing changes in rainfall patterns. Thus, the drought of 1972 and 1973 was marked as the first major climatic event in the Sahel. These climatic disturbances greatly affected economies as well as ecosystems (CILSS, 2006). 
According to Wilkinson and al (2015), the case of drought in Mali highlights the complex and dynamic link between climate extremes, poverty and development. Thus Mali is an example of how recurrent droughts can entrench poverty and undermine resilience. Meanwhile, agriculture is a major economic sector in Mali, employing almost $80 \%$ of the population and accounting for more than $40 \%$ of GDP and 3/4 of exports, and is characterized by low productivity and a lack of modern agricultural technologies (Chauvin and al. 2012). Despite being an important sector of the national economy, as Mali's agriculture is essentially rain-fed, it is highly dependent on the climate and therefore vulnerable to climate change.

In response to climate change and climate variability, two approaches with economic considerations have often been used in the literature to assess the impacts of climate change on agriculture: the production function or agronomic approach and the Ricardian approach.

The first is an experimental approach that seeks to measure the direct impacts of climate change on different crops. This approach attempts to directly measure the response mechanism of crops to climatic hazards while simulating crop yields using agronomic models. Authors who have adopted this approach include Adams and al (1990), Kane and al (1991), Kaiser and al (1993), Reilly and al (1994), Rosenzweig and Iglesias (1994) and Rosenzweig and Parry (1994), Bassu and al (2014). In Mali, Chaisemartin and al (2010) use scenario simulations to estimate the economic losses that Mali will experience in 2030. They estimate that climate change could lead to losses of about US\$300 million per year (about $15 \%$ of the value of agriculture and livestock) under the pessimistic scenario. These losses would be US\$120 million per year (6\% of the value of agriculture and livestock) under the optimistic scenario. These results are more alarmist than those previously found by Butt and al (2005) who predict that Mali will suffer economic losses of between US\$ 96 and 116 million. They arrive at this result using projections of climate change induced by greenhouse gas emissions by 2030 and carried out using HADCM and CGCM climate models. Sissoko and al, 2018 adopts the production function approach to assess and compare the resilience of millet, sorghum and maize to climate variability in the regions of Sikasso and Segou. These authors find that the level of resistance of cereals to climate variability differs from one region to another due to the bioclimatic zoning of the study site. For example, cereals are more related to the climate in the Sikasso region than in the Ségou region. However, these models do not take into account the possibility for farmers to adapt to a new climatic condition (Mendelsohn, 1994).

The second, the Ricardian approach is an alternative to estimates of production functions (Mendelsohn and al. 1994). It takes its name from the theory of the classical economist David Ricardo (1817) that, in a market of pure and perfect competition, ground rent is equal to profit.

Despite the abundant literature on the subject of agriculture and climate change, there are still gaps in the literature to be filled. By using a spatial econometric framework, we take into account the spatial dependence and heterogeneity present in the data, which are not properly accounted for or completely ignored in the previous literature.

Thus, the objective of this study is to assess the impact of climate change on agriculture in Mali. It is therefore a question of assessing the total, direct and indirect effects of rainfall and temperature, floods and droughts on the yields of the main cereal crops in Mali through spatial panel modelling.

\section{Materials and methods}

\subsection{Study zone}

Situated between 10 and $25^{\circ}$ north latitude, Mali has a dry tropical climate with $65 \%$ of its territory in semidesert and desert conditions. The national territory is currently divided into 10 administrative regions, which are themselves subdivided into circles and communes. The population, estimated at around 20 million inhabitants in 2020 , with a growth rate of $3.65 \%$ per year, is unevenly distributed over the territory with a high demographic concentration in the southern part of the country.

The country's climate is characterized by the alternation of two seasons: 
- A dry season whose duration varies from seven (7) months in the North (November to May) to six (6) months in the South (November to April), characterized by hot and dry winds blowing from the North-East to the South-West, whose duration varies from 6 to 9 months;

- And a wet or wintering season, May to October in the South, June to October in the North with more or less marked inter-seasons corresponding to months "neither rainy nor dry", dominated by humid winds from the Gulf of Guinea (the monsoon), blowing from the South-West to the North-East, bringing rains for 3 to 4 months depending on the zone (National Direction of Meteorology, 2016).

In addition, there are four climatic zones (figure 1):

Agroecological Zones in Mali

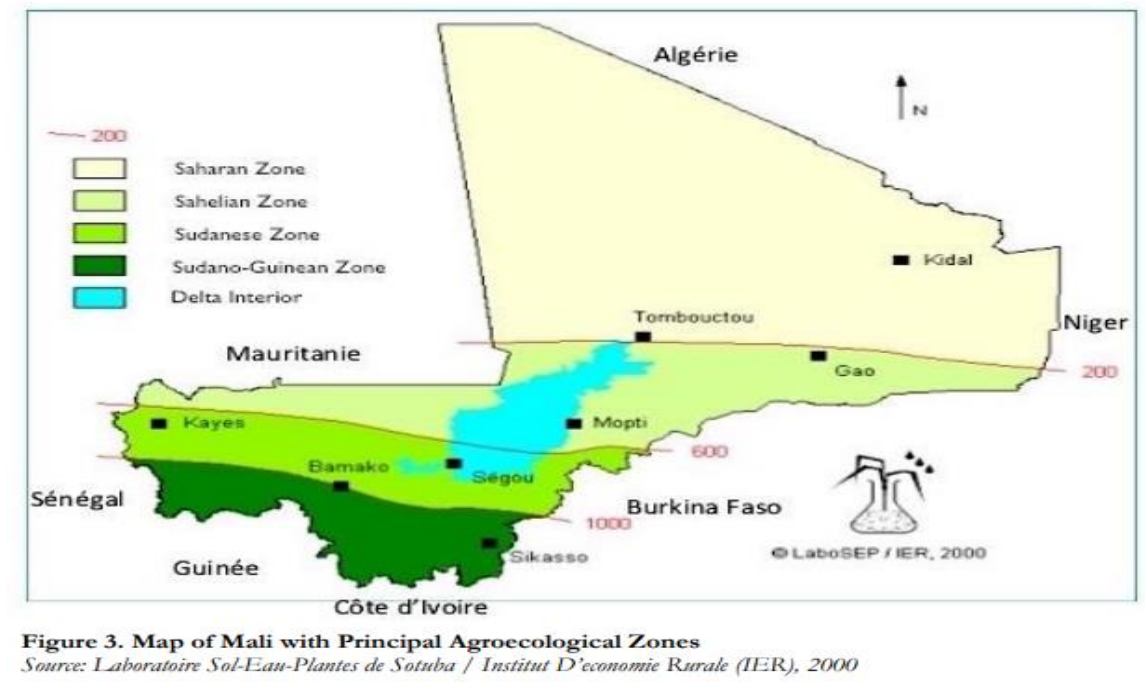

- Saharan in the north (annual rainfall $<200 \mathrm{~mm}$ );

- Sahelian in the center (annual rainfall between $200 \mathrm{~mm}$ and $600 \mathrm{~mm}$ );

- Sudanese (annual rainfall between $600 \mathrm{~mm}$ and $1000 \mathrm{~mm}$ ) and

- Sudano-Guinean in the south (rainfall> $1000 \mathrm{~mm}$ ).

Mali's geographical position places it in a Sudano-Sahelian zone that is particularly exposed to climate change, which makes agriculture, the country's main activity, precarious. Changes in climatic conditions, particularly since the droughts of 1970 and 1980, have led to a more arid climate throughout the country, a trend towards an overall decrease in useful rainfall of $20 \%$ and a $200 \mathrm{~km}$ southward displacement of isohyets, which has greatly weakened the agricultural sector, which is mainly food and rain-fed (DNM, 2018).

To quantify these future impacts due to climate change, projection scenarios have been developed. Thus, the IPCC modelling and the different scenarios developed in the third communication on climate change in Mali. The most plausible climate scenario foresees on average for the horizon 2100 an increase in temperature of $3{ }^{\circ} \mathrm{C}$ and a decrease in rainfall of $22 \%$ compared to normal over the entire territory and an increase in extreme climate events (MEADD, 2018).

\subsection{Methodology}

\section{a. Sampling}

The data on harvested area (in Hectare, $\mathrm{Ha}$ ) and crop yields (in $\mathrm{Kg} / \mathrm{Ha}$ ) come from the Conjuncture Agricultural Survey (EAC) and are available from the Planning and Statistics Unit of the Rural Development Sector (CPS / SDR) of the Ministry of Agriculture. The data are annual and cover the period from 1988 to 2017. The EAC is a sample survey. It differs from a census in that not all farms are surveyed. It is carried out on a limited number of observation units (farms in rural areas, households in urban areas) selected from the larger set. The data on the sample must be multiplied by extrapolation coefficients in order to obtain data valid for all the regions of Mali. The crops covered by the survey are essentially cereals 
(millet, sorghum, rice, maize, fonio, wheat, etc.), cowpea, voandzou, sesame, groundnuts, etc. The data on the sample should be multiplied by extrapolation coefficients in order to obtain data valid for all regions of Mali. This is how we selected cereals such as millet, maize and sorghum. In addition to rice, these cereals are the main staple of the Malian population's diet.

The climate data come from the database of the National Meteorological Service of Mali (Mali Meteorological). These data include average monthly temperatures and average monthly rainfall for the period 1988 to 2017.

\section{b. Collection of data}

AEC data collection generally consists of: enumerating the holdings in the sample Enumeration Sections (ES) and drawing the 10 sample holdings; enumerating and measuring all plots on the sample holdings and drawing sample plots (1/3) by pure crop type or crop combination; placing yield squares; administering all questionnaires; harvesting the squares and weighing the products from the squares.

\subsection{Data analysis}

In this paper, the production function approach through spatial panel modelling is adopted to meet our main objective of assessing the impact of climate change on Malian agriculture. The choice of this approach was mainly based on issues related to data availability: more precisely, data were only available on an aggregated basis for the selected crops. In addition, we seek to measure the direct, indirect and total effect of weather conditions on yield without using intermediate variables. In addition, the absence of functional land markets in Mali makes it difficult to determine land values and therefore makes the Ricardian model inapplicable.

The structure of our data guides us towards panel modelling. We estimate above all a standard linear panel data model, i.e. a model without spatial autocorrelation. This model can be used as a reference for the estimation results of spatial panel data models as well as for checking the robustness of these estimation results (Yang and al., 2017). According to Baltagi (2005), Baum and Christopher (2006), the standard linear regression model (SLM) is written:

$$
\begin{aligned}
Y_{i t}=X_{i t} \beta+\alpha_{i}+\varepsilon_{i t} \\
\varepsilon_{i t} \sim N\left(0 ; \sigma_{s}^{2}\right)
\end{aligned}
$$

Where $Y_{i t}$ is the variable explained, $i$ refers to individuals, and $j$ constitutes the regions ${ }^{1}(\mathrm{~N}=5) . t$ is the dimension of the time series, i.e. 1988 to $2017 . X_{i t}$ is $1 \times k$ observations of the explanatory variables and $\beta$ is the $k \times 1$ vector of indeterminate coefficients. $\alpha_{i}$ is an individual effect that cannot be directly observed and quantified and $\varepsilon_{i t}$ is a term of disturbance that varies with the individual and over time. If $\alpha_{i}$ is related to $X_{i t}$, the panel data model model is a fixed-effect model; otherwise it is a random-effect model (Fotheringham and Rogerson, 2008, cited in Guliyev, 2020).

\section{c. Specification of the spatial panel model}

It is important to stress that before any exploratory spatial data analysis (ESDA), it is necessary to specify the spatial links that exist between the elements involved (districts, cities, regions, countries, etc.). Basically, the degree of spatial proximity between geographically located objects is obtained through the representation of a square matrix called a weighting matrix or spatial weighting matrix, noted W. According to Le Gallo (2002), two main categories can be distinguished of matrix: the adjacency matrices and the generalized weight matrices.

\section{Contiguity matrix}

To study the interactions between a large numbers of regions, the simple binary contiguity matrix is used, whose components take the value 1 when the regions share a common border and 0 otherwise. 


$$
\boldsymbol{w}_{i j}=\left\{\begin{array}{l}
1 \text { if regions } i \text { and } j \text { contiguous } \\
0 \text { if not }
\end{array}\right.
$$

For the same region, there can be no contiguity. In other words, a region is not contiguous to itself. In this case,

$$
W_{i j}=0 \quad \forall i=j
$$

To find out the number of regions contiguous to a region $i$ the elements of the line must be added together. $i$ of the same contiguity matrix either:

\footnotetext{
${ }^{1}$ Mali is divided into ten administrative regions, including five northern regions namely Timbuktu, Gao, Kidal, Taoudéni and Ménaka. Since the security crisis in northern Mali in 2012, most meteorological stations have been sabotaged, leaving a lot of missing data on the series of climatic variables (temperature, precipitation, sunshine, etc.) and therefore we have excluded these northern regions in our analysis.
}

$$
L_{i}=\sum_{j}^{N} W_{i j}
$$

\section{- Generalized weight matrix}

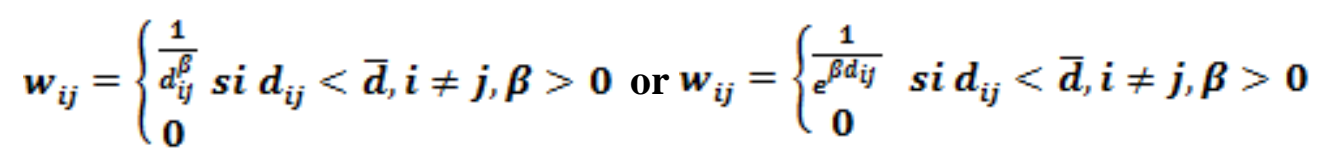

$\boldsymbol{\beta}$ is a distance decay parameter set a priori, $\overline{\boldsymbol{d}}$ is the threshold value beyond which it is assumed that there is no direct interaction between the region $i$ and the region $j$.

Contiguity matrix and the generalized weight matrices are often standardized s are equal to:

With standardization, the weights are then between 0 and 1 and facilitates the comparison of spatial parameters in spatial processes between models. Harris and al (2011) point out, however, that the concept of distance is itself unclear, so in our study we will use the contiguity matrix.

\section{d. Spatial models}

Building on the seminal spatial econometrics paper by Manski (1993), Elhorst (2010) will establish a series of classifications of the main spatial econometrics models. These spatial models include the Spatial Autoregression Model (SAR), the Spatial Error Model (SEM), the Spatial Autocorrelation Model (SAC) and the Spatial Durbin Model (SDM). In this paper, grain yield was modelled using the Ordinary Least Squares (OLS) method (Standard Linear Regression Model (SLM)) and the principles of Maximum Likelihood (ML), depending on whether or not the spatial argument is included in the analysis.

\section{i. Spatial Autoregression Model (SAR)}

The SAR regression model follows a self-regression process, which is indicated by the presence of a dependency relationship between a set of observations or spatial units (Saputro et al, 2019). Therefore, its formula includes the term spatial shift of the dependent variable. Developed by Anselin and al (2008) then improved by Elhost (2010) in our case, the agricultural production of region $i$ is explained by the exogenous variables specific to $i$, but it is also explained by the exogenous variables of i's neighbors. The model is also characterized by the presence of a spatial diffusion effect, this effect is based on the error process, a random is also explained by the exogenous variables of i's neighbors. The model is also characterized by the presence of a spatial diffusion effect, this effect is based on the error process, a random shock in region $\mathrm{i}$ disrupts the agricultural production of region i but also the production of neighboring regions. The model is 
presented as an adjustment of the standard panel model with a fixed effect and a random effect, which can be written as follows:

$$
Y_{i j}=\sum_{j=1}^{N} \rho W_{i j} Y_{j t}+X_{i t} \beta+\mu_{i}+\lambda_{t}+\varepsilon_{i t}
$$

Where: $Y_{i j}$ is the agricultural yield of the region $i$ on the date $t, X_{i t}$ represents the matrix of exogenous variables, the set of weights allows to build the weighting matrix $W_{i j}$, the value of $\rho$ reflects the degree of spatial dependence between the units observed (Gelfand and al., 2010), and is between 0 and 1. If $\rho$ close to 1 close to 1 then the degree of correlation is strong and therefore the agricultural production of the region $i$ is highly dependent on neighboring observations. Moreover, if $\rho$ to statistical significance, it demonstrates the existence of a significant spatial dependence between the dependent variables, i.e. agricultural production in a region depends on contiguous regions, that is to say that the agricultural production in a region depends on the contiguous regions, $\beta$ is the coefficient of spatial self-regression.

$\mu_{i}$ and $\lambda_{t}$ are the individual and temporal effects respectively.

$\varepsilon_{i t}$ : the vector of model residuals subject to standard least square assumptions.

\section{ii. Spatial Error Model (SEM)}

In this case, the random $\varepsilon$ term follows, as in the case of the variable explained in the model with spatial autoregression, a spatial autoregressive process. This model looks like this:

$$
\begin{aligned}
Y_{i j}=X_{i t} \beta+\mu_{i}+ & \lambda_{t}+\varepsilon_{i t} \\
\varepsilon_{i t} & =\sum_{j=1}^{N} \rho W_{i j} \varepsilon_{i t}+\eta_{i t}
\end{aligned}
$$

With $\rho W_{i j}$ : matrix of spatial autocorrelation effects

$\eta$ : Vector of independent random terms with zero expectation, $\mathrm{E}(\eta)=0$ and variance $\sigma^{2}$.

\section{iii. SAC model}

We consider a cross-sectional spatial autoregressive model with endogenous variables and spatial autoregressive perturbations (SAC) also called SARAR model, allowing a higher order spatial dependence in the dependent variable, exogenous variables and spatial errors. The model is:

$$
\begin{array}{r}
Y_{i t}=\sum_{j=1}^{N} \rho W Y_{j t}+X_{i t} \beta+\alpha_{i}+\mu_{i}+\varepsilon_{i t} \\
\varepsilon_{i t}=\sum_{j=1}^{N} \delta W \varepsilon_{i t}+\eta_{i t}
\end{array}
$$

$W Y_{j t}, W \varepsilon_{i t}$, and $\varepsilon_{i t}$ are $\mathrm{n} \times 1$ spatial shifts for the exogenous variable, the dependent variable and the error terms. $\rho, \alpha_{i}$, and $\mu_{i}$ are scalar parameters; $X_{i t}$ is an $\mathrm{n} \times 1$ vector of innovations.

\section{iv. Durbin Spatial Model (SDM)}

The SDM includes dependent spatial variables and explanatory variables. It uses the marginal effects of the explanatory variables of neighboring regions / states based on the SAR model. The common specification for SDM is as follows: 


$$
Y_{i t}=\sum_{j=1}^{N} \rho W Y_{j t}+X_{i t} \beta+\sum_{j=1}^{N} \delta W X_{j t}+\mu_{i}+\lambda_{t}+\varepsilon_{i t}
$$

$Y_{i t}$ : The yield of food crops in the region ${ }^{2} i$ at the date $t$

$\sum_{j=1}^{N} W Y_{j t}$ : The yield of food crops in regions near to $i$

$X_{i t}$ : Represents the explanatory variables of the region $i$

$\sum_{j=1}^{N} W X_{j t}$ : The explanatory variables of the neighboring regions to $i$

$\mu_{i}+\lambda_{t}$ : are the individual and temporal effects of the region $i$ at the moment $t$

Under the hypothesis H0: $\gamma=0$, the spatial Durbin model becomes a Spatial Autoregression Model (SAR). Similarly, if $u=Y-X \cdot \beta$, we find the SEM model. This model is thus more robust to poor choice of specification even in the presence of spatially auto-correlated errors (SEM) ${ }^{3}$.

Compared to standard linear panel data models, one of the peculiarities of spatial panel data models are their ability to take into account spatial effects, such as spatial dependence and spillover effects (Guliyev, 2020). Another advantage compared to the spatial model based on cross-sectional and temporal data is that the spatial panel data model can capture the individual heterogeneity of spatial units - i.e. individual effects - and can escape missing variables and estimation errors more efficiently (Elhorst, 2014).

Variables and expected signs of the explanatory variables: The study used the following variables and the expected signs of the variables included depending on the nature of the variables used presented in table 1.

\footnotetext{
${ }^{2}$ Malian agriculture is dominated by dry cereals (millet, sorghum, maize and rice), which constitute the staple of the diet. Rice is a special crop and is usually irrigated. Therefore, excluded in this part.
}

${ }^{3}$ LE SAGE et al. 2009.

Table 1: Description of variables

\begin{tabular}{|c|c|}
\hline Variable & Description \\
\hline $\ln \mathrm{Rdt}$ & Crop yield in logarithm $(\mathrm{Kg} / \mathrm{Ha})$ \\
\hline $\operatorname{lnSup}$ & Area in logarithm $(\mathrm{Ha})$ \\
\hline lnTemp_moy & Average temperature in logarithm $\left({ }^{\circ} \mathrm{C}\right)$ \\
\hline lnTemp_sq & Average temperature squared in logarithm $\left({ }^{\circ} \mathrm{C}\right)$ \\
\hline lnPrec_moy & Average rainfall in logarithm $(\mathrm{mm})$ \\
\hline lnPrec_sq & Average rainfall squared in logarithm $(\mathrm{mm})$ \\
\hline $\operatorname{lnTemp} *$ Prec & Temperature $*$ Rainfall \\
\hline $\operatorname{lnCVT}$ & $\begin{array}{l}\text { Coefficient of Temperature Variation in } \\
\text { logarithm }\end{array}$ \\
\hline $\operatorname{lnCVP}$ & Coefficient of Rainfall Variation in logarithm \\
\hline Sech & Drought \\
\hline Flood & Flood \\
\hline
\end{tabular}

\section{Source : Author's calculation}

\section{Temperature and precipitation data}

The average monthly temperature (Temp_moy) and average monthly rainfall (Prec_moy) are based on the growing season for cereals in the regions of Mali (June to October). We consider that rainfall and off-season 
temperatures would not affect cereal production. The monthly average temperature and the monthly average rainfall value reflect inter-seasonal variability.

\section{Data on the seasonal variation coefficient of the temperature and of art rainfall}

The coefficient of seasonal variation of the temperature (CVT) and seasonal variation of rainfall (CVP), captures seasonal variability s temperature and precipitation and taken as seasonal ratio the standard deviation to the mean of the temperature and rainfall, respectfully.

\section{Floods and droughts data}

Thanks to the SPI (Standardized Precipitation Index), it is possible to identify periods of drought and flooding (Blanc, 2012). In this study, droughts and floods begin when the SPI reaches values of -1.5 and +1.5 , respectively, and end when the index returns to a positive and negative value, respectively.

Excel 2010, GeoDa and STATA 14 software are used in data analysis.

\section{Results and discussion}

Table 2 presents the descriptive statistics (mean (Mean), standard error (St.Dev), minimum (Min) and maximum (Max)) of the study variables.

Thus, the average maize yield value $(\mathrm{Kg} / \mathrm{Ha})$ is 1276.84 with a volatility of $607.36(\mathrm{Kg} / \mathrm{Ha})$. In addition, the minimum and maximum values of maize yield $(\mathrm{Kg} / \mathrm{Ha})$ are 377 and 3006.97 respectively.

The average temperature fluctuates between 26.2 and $31.53^{\circ} \mathrm{C}$. The coefficient of temperature variation has a standard deviation of $0.014 \mathrm{~mm}$, which indicates that there is little year-to-year seasonal variation in temperature.

As far as precipitation is concerned, the seasonal average value is $134.61 \mathrm{~mm}$. It varies between 45.92 and $252.62 \mathrm{~mm}$ with a variability of $44.01 \mathrm{~mm}$. The coefficient of variation of precipitation has an average of $0.570 \mathrm{~mm}$ and the minimum and maximum values are between 0.23 and 1.04 .

Table 2: Descriptive statistics of the control variables

\begin{tabular}{|c|c|c|c|c|}
\hline Variable & Mean & St. Dev. & Min & Max \\
\hline Rdt & 1276,849 & 607.3619 & 377 & 3006,972 \\
\hline Sup & 57513.65 & 77567.95 & 4 & 446832 \\
\hline Temp_avg & 28.76 & 1.51 & 26.2 & 31.53 \\
\hline Prec_moy & 134.61 & 44.01 & 45.92 & 252.62 \\
\hline CVT & .0483559 & .0149194 & .0239784 & .1081346 \\
& & & & \\
\hline CVP & .5705424 & .1661198 & .2316991 & 1.049772 \\
& & & & \\
\hline
\end{tabular}

\section{Source: Author's calculation, data from CPS / Agricultural and Mali-Meteorological}

\section{a. Spatial dependency test}

Standard linear panel data models assume that there is no cross-sectional correlation between observation units. Ignoring potential cross-sectional dependence can produce biased estimates (Le Sage and Pace, 2009).

The interactions between administrative regions in Mali suggest that spatial spillovers may lead to a crossdependency of maize yields between these regions. 
Figure 1 shows the distribution of average yields over the period 1988-2017: different colors identify the quartiles of the distribution, with darker areas corresponding to higher average yields.

The average maize yields are concentrated in the Sikasso region, while the Mopti particular has relatively lower average yields.

To formally test cross-sectional dependence, we estimate linear fixed-effect (FE) and random-effect (RE) panel data models and perform the CD test of Pesaran (2004) for cross-sectional dependence. The results of the standard panel model are reported in Table 3

Table 3. Panel data model results without spatial effects

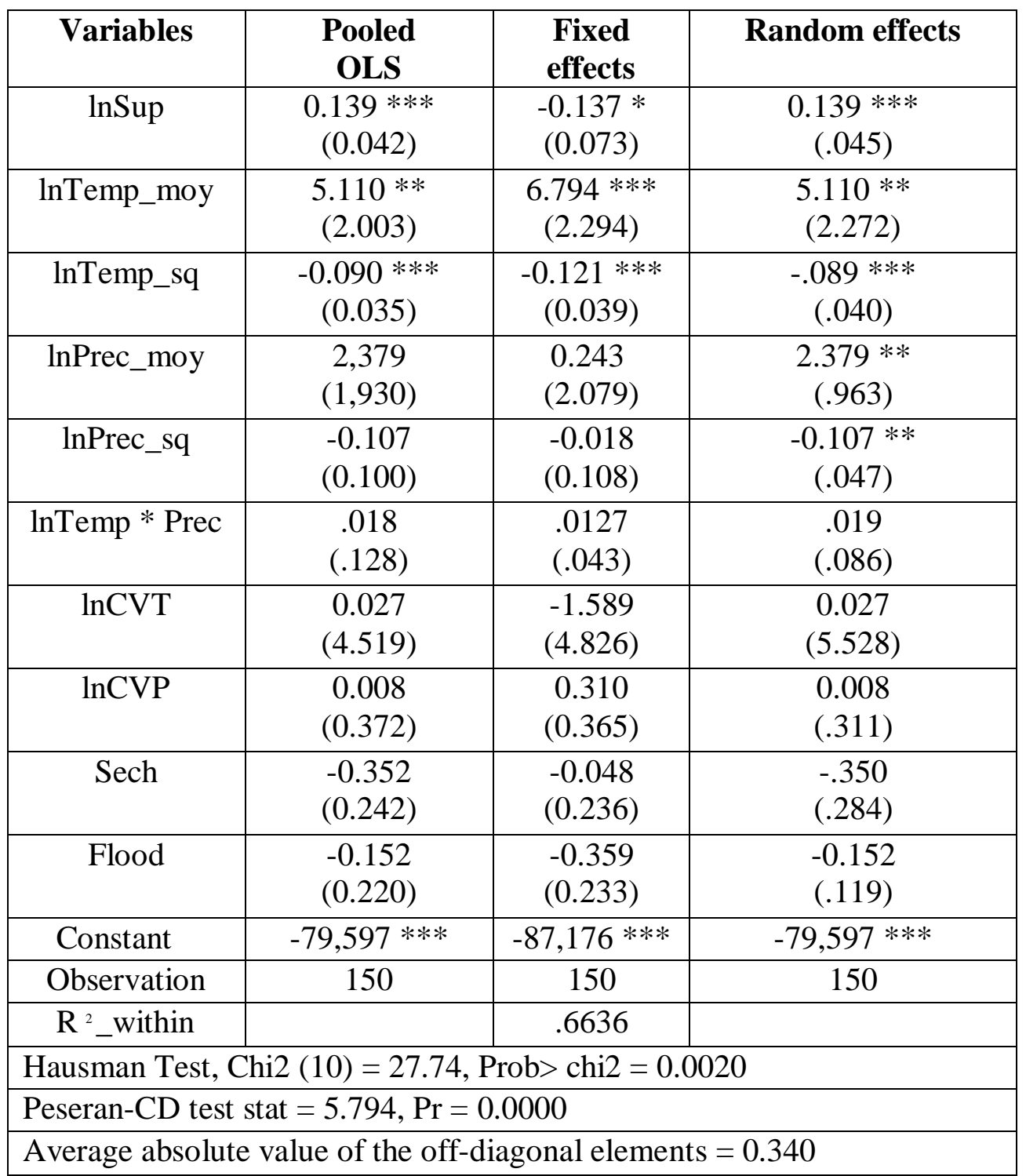

Standard errors in parentheses. $* \mathrm{p}<0.10, * * \mathrm{p}<0.05, * * * \mathrm{p}<0.01$

In panel modelling, the choice of models is guided by tests. The Hausman test allows to arbitrate between a fixed effect model and a random effect model. And, according to the Hausman test, the hypothesis of the random effect model is strongly rejected (Prob>chi $2=0.0020<0.05$ ). As we can also see, the CD test strongly rejects the null hypothesis of cross-sectional non-dependence $(\operatorname{Pr}=0.0000)$. Moreover, the mean absolute value of the off-diagonal elements of the cross-correlation matrix of the residuals is 0.340 , which indicates a possible cross-sectional dependence (De Hoyos and Sarafidis, 2006). Therefore, there is sufficient evidence to suggest the presence of cross-sectional dependence under a fixed-effect (FE) specification.

To summarize, we controlled for fixed effects in the following spatial regression models. 


\section{b. Model estimation (SDM and SAR)}

The estimation of the models (SDM and SAR) reveals the spatially autoregressive coefficients $(\rho)$ positive and significant for the SAR model at the $1 \%$ threshold. In the case of the SDM model, it is negative and significant only at the $1 \%$ threshold.

The opposite sign of $\rho$ for both results indicates that spatial interactions between regions vary considerably with climate. Furthermore, the SDM model reveals that spatial autocorrelation is significant for the explanatory variables, except for the variables coefficients of variation of temperature, precipitation, droughts and floods).

On the other hand, autocorrelation is positive and has a significant impact on temperature and precipitation. Similarly, this coefficient is negative for area, precipitation, temperature squared and the interaction between temperature and precipitation. It follows that extremely high values are correlated with extremely low values in space.

Table 4: Results of panel data models with spatial effects on maize yield

\begin{tabular}{|c|c|c|c|c|c|c|}
\hline & \multicolumn{3}{|c|}{ SAR } & \multicolumn{3}{|c|}{ SDM } \\
\hline Variable & Coefficient & t-statistics & p-Value & Coefficient & t-statistics & p-Value \\
\hline $\operatorname{lnSup}$ & .05912 & .0502 & 0.239 & -.15060 & .0640 & 0.019 \\
\hline lnTemp_moy & 7.7027 & 2.0617 & 0.000 & 5.5909 & 2.3478 & 0.017 \\
\hline lnTemp_sq & -1338 & .03567 & 0.000 & -.0992 & .0407 & 0.015 \\
\hline lnPrec_moy & 1.2250 & 1.8563 & 0.509 & -.3593 & 1.6134 & 0.824 \\
\hline lnPrec_sq & -.1320 & .3894 & 0.735 & .1162 & .3332 & 0.727 \\
\hline lnTemp * Prec & -.0009 & .0011 & 0.422 & & & \\
\hline $\operatorname{lnCVT}$ & -.2350 & .1115 & 0.035 & -6.056 & 3,613 & 0.094 \\
\hline $\operatorname{lnCVP}$ & -.1803 & .2356 & 0.444 & .3792 & .3048 & 0.214 \\
\hline Sech & -.3246 & .2306 & 0.159 & -.2326 & .1844 & 0.207 \\
\hline Flood & -.4254 & 2432 & 0.080 & -.1002 & .1884 & 0.595 \\
\hline $\mathrm{W} * \operatorname{lnSup}$ & & & & -.09173 & .04179 & 0.028 \\
\hline $\mathrm{W} * \operatorname{lnTemp\_ moy}$ & & & & 5.6395 & 1,887 & 0.003 \\
\hline $\mathrm{W} * \operatorname{lnTemp\_ sq}$ & & & & -.0971 & .0329 & 0.003 \\
\hline $\mathrm{W} *$ lnPrec_moy & & & & -4.7048 & 2.6446 & 0.075 \\
\hline InPrec_sq & & & & 1.0633 & .5625 & 0.059 \\
\hline $\mathrm{W} * \ln T e m p *$ Prec & & & & -.1047 & .00019 & 0.068 \\
\hline $\mathrm{W} * \ln C V \mathrm{~T}$ & & & & -.1 .9412 & 3.5213 & 0.581 \\
\hline $\mathrm{W} * \operatorname{lnCVP}$ & & & & .3784 & .2812 & 0.178 \\
\hline $\mathrm{W} * \mathrm{Sech}$ & & & & -.1865 & .4529 & 0.680 \\
\hline $\mathrm{W} *$ Flood & & & & .2147 & .1750 & 0.220 \\
\hline $\mathrm{P}$ & .0909 & .0334 & 0.0007 & -.2370 & .04844 & 0.000 \\
\hline$\sigma^{\wedge} 2$ & .2573 & .0676 & 0.000 & .1314 & .0277 & 0.000 \\
\hline Observation & 150 & & & 150 & & \\
\hline Log Likelihood & -107.8246 & & & -103.5653 & & \\
\hline
\end{tabular}




\section{Source : Author's calculation}

However, the interpretation of the coefficients of the spatial model remains delicate in the presence of a spatially shifted variable. $W Y$. These coefficients are not directly comparable to those of the non-spatial model. The effects of the explanatory variables can thus be distinguished according to two components: the direct effect and the indirect effect. Indeed, for a region $i$ if there is a direct effect of the effect of the direct effect on a variable, an explanatory variable $\mathrm{X}$ and a dependent variable $\mathrm{Y}$, the direct effect can be interpreted as the impact on $Y_{i}$ following a variation of $X_{i}$. In other words, the impact of a variation of $\mathrm{X}$ specific to the region $i$ on the endogenous variable $Y_{i}$. On the other hand, the indirect effect is the impact on $Y_{i}$ the sum of the variations of $\mathrm{X}$ in neighboring regions $\sum X_{j}$. The indirect effect is the variation in $Y_{i}$ following a variation of $\mathrm{X}$ in the neighboring regions $\mathrm{j}$. It is sometimes referred to as the spillover effect.

In order to highlight the direct and indirect effects, we can carry out Wald and likelihood ratio (LR) tests in order to select the most appropriate model.

\section{c. The choice of spatial models}

Regarding model selection, when testing H0: $\theta=0$ using the Wald and LR tests, the SAR is always rejected against the SDM for both results and also the SEM is rejected against the SDM (Table 5). Given this consistent evidence and considering that spatially shifted variables also control the relevant omitted variables, we focus on the SDM.

Table 5: Wald tests and LR test to select the appropriate model

\begin{tabular}{|l|c|c|}
\hline \multicolumn{3}{|c|}{ WALD TEST } \\
\hline $\operatorname{SAR}\left(H_{0}\right)-\operatorname{SDM}\left(H_{1}\right)$ & 17.70 & $(0.0388)$ \\
\hline $\operatorname{SEM}\left(H_{0}\right)-\operatorname{SDM}\left(H_{1}\right)$ & 15.35 & $(0.0817)$ \\
\hline \multicolumn{3}{|c|}{ LR TEST $($ ML estimate $)$} \\
\hline $\operatorname{SAR}\left(H_{0}\right)-\operatorname{SDM}\left(H_{1}\right)$ & 20.34 & 0.0091 \\
\hline $\operatorname{SEM}\left(H_{0}\right)-\operatorname{SDM}\left(H_{1}\right)$ & 23.31 & 0.0030 \\
\hline
\end{tabular}

\section{Source: Author's calculation}

* Likelihood ratio tests: the nested model (SAR or SEM) versus the more general model (SDM). The asymptotic distribution of the test statistic is one (8) with degrees of freedom equal to the number of restrictions imposed by the corresponding nested model. The values in parentheses are the associated critical probabilities.

\section{d. Analysis of spatial effects}

In order to further investigate the possible sources of impact, we calculate direct, indirect and total effects. The average direct, indirect and total effects of our explanatory variables are presented in Table 6.

The results show us that average seasonal temperature and rainfall have direct positive and significant effects on maize yield, while the area planted and the interaction between temperature and rainfall have direct negative and significant effects on maize yield. In other words, a $1 \%$ increase in temperature and rainfall over the region $i$ leads respectively to a positive variation of $4.84 \%$ and $0.20 \%$ on the yield maize in our region $i$. This can be explained by the fact that maize production in Mali is mainly concentrated in southern Mali, which remains the wettest region in the country, and also by the impact of the maize variety change project launched by the Institute of Rural Economy (IER) in the southern part of Mali since the 1970 s. In addition, a $1 \%$ increase in the area sown and the interaction between temperature and rainfall leads to a negative variation of $0.14 \%$ to $0.10 \%$ in maize yield in the region $i$ respectively.

With regard to estimates of indirect impacts, average indirect effects can more fully reflect the actual effect of influencing factors (Guliyev, 2020). 
The indirect effects of temperature is equal to 4.17 (prob<0.05), indicating that a $1 \%$ increase in the temperature of the regions around $i$ would result in a positive $4.2 \%$ change in maize yield in the region. $i$. However, the indirect effect of the precipitation variable is negative and significant at the $1 \%$ threshold. In other words, a $1 \%$ increase in rainfall in all other regions would decrease the maize yield in a typical region by $0.03 \%$.

Table 6: Estimates of direct, indirect and total effects on maize yield

\begin{tabular}{|c|c|c|c|}
\hline & \multicolumn{3}{|c|}{ SDM } \\
\hline & Total & Direct & Indirect \\
\hline Variable & $\begin{array}{c}\text { Coefficient } \\
\text { (t-Value) }\end{array}$ & $\begin{array}{c}\text { Coefficient } \\
\text { (t-Value) }\end{array}$ & $\begin{array}{c}\text { Coefficient } \\
\text { (t-Value) }\end{array}$ \\
\hline $\operatorname{lnSup}$ & $\begin{array}{c}-.1952 * * * \\
(0.003)\end{array}$ & $\begin{array}{c}-.1435 * * \\
(0.029)\end{array}$ & $\begin{array}{c}-.0516 \\
(0.208)\end{array}$ \\
\hline lnTemp_moy & $\begin{array}{c}9.018 * * * \\
(0.000)\end{array}$ & $\begin{array}{c}4.8468 * \\
(0.057)\end{array}$ & $\begin{array}{c}4.1713 * * \\
(0.033)\end{array}$ \\
\hline lnTemp_sq & $\begin{array}{c}-.1576 * * * \\
(0.000)\end{array}$ & $\begin{array}{c}-.08656 * \\
(0.051)\end{array}$ & $\begin{array}{c}-.07113 * * \\
(0.039)\end{array}$ \\
\hline lnPrec_moy & $\begin{array}{c}4.0123 * \\
(0.099)\end{array}$ & $\begin{array}{c}.1982 * * \\
(0.047)\end{array}$ & $\begin{array}{c}-.02586 * * * \\
(0.008)\end{array}$ \\
\hline lnPrec_sq & $\begin{array}{l}.9384 * \\
(0.069)\end{array}$ & $\begin{array}{c}-1411 \\
(0.694)\end{array}$ & $\begin{array}{c}1.0795 * \\
(0.056)\end{array}$ \\
\hline $\operatorname{lnTemp} *$ Prec & $\begin{array}{c}-.0716 * * * \\
(0.002)\end{array}$ & $\begin{array}{c}-.1047 * \\
(0.068)\end{array}$ & $\begin{array}{l}-.29461 \\
(0.324)\end{array}$ \\
\hline $\operatorname{lnCVT}$ & $\begin{array}{c}-6.3786 \\
(0.014)\end{array}$ & $\begin{array}{c}-5.7215 \\
(0.135)\end{array}$ & $\begin{array}{c}-6.3786 \\
(0.114)\end{array}$ \\
\hline $\operatorname{lnCVP}$ & $\begin{array}{c}.62035 * \\
(0.073)\end{array}$ & $\begin{array}{c}.3098 \\
(0.344)\end{array}$ & $\begin{array}{l}.6203 * \\
(0.073)\end{array}$ \\
\hline Sech & $\begin{array}{l}-.3714 \\
(0.375)\end{array}$ & $\begin{array}{l}-.2108 \\
(0.269)\end{array}$ & $\begin{array}{c}-.24622 * * * \\
(0.017)\end{array}$ \\
\hline Flood & $\begin{array}{l}.1042 \\
0.652\end{array}$ & $\begin{array}{l}-.1404 \\
(0.450)\end{array}$ & $\begin{array}{l}-.3713 \\
(0.375)\end{array}$ \\
\hline
\end{tabular}

\section{Source : Author's calculation}

Associated probability in parentheses

$* \mathrm{p}<0.10, * * \mathrm{p}<0.05, * * * \mathrm{p}<0.01$

The analysis of the indirect effect of the drought variable (Sech), we note that the elasticity of the explanatory variable (Sech) at the expected and significant sign.

The inter-seasonal variation in rainfall (VSC) is significant at the 5\% level and is negatively related to the effects of maize. However, an increase in seasonal rainfall variability (lnCVP) of $1 \%$ from one season to the next over the region $i$ would reduce maize yields by about $0.62 \%$ of a kilogram per hectare in all other regions. This indirect impact takes into account the fact that the inter-seasonal variation in rainfall (lnCVP) 
has a negative impact on the yield in other regions, which in turn negatively influences the yield in our typical region due to the presence of a positive spatial dependence on yields in neighboring regions.

We also find that the direct and total effect of temperature and rainfall are significantly positive. The increase in temperature or rainfall will significantly increase maize yield in region $i$ and subsequently increase maize yield in all regions. In other words, a 1\% increase in temperature would result in an increase in maize yield in region $i$ of $4.84 \%$ and regional yield of $9.01 \%$. Similarly, a $1 \%$ increase in rainfall would increase maize yields in the region $i$ of $0.20 \%$ and the regional yield of $4.01 \%$. This proves that temperature and rainfall are beneficial for maize cultivation up to a certain threshold, above which temperature and rainfall can have adverse effects on the average maize yield.

Second, the Coefficient of Variation in rainfall ( $\operatorname{lnCVP}$ ) has the expected positive effect, while the area sown and the interaction between temperature and rainfall have a negative impact on maize yield. In addition, the intra-seasonal temperature variability has a considerable overall effect on maize yield.

Table 7: Estimates of direct, indirect and total effects on millet yield

\begin{tabular}{|c|c|c|c|}
\hline & \multicolumn{3}{|c|}{ SDM } \\
\hline & Total & Direct & Indirect \\
\hline Variable & $\begin{array}{c}\text { Coefficient } \\
\text { (t-Value) }\end{array}$ & $\begin{array}{c}\text { Coefficient } \\
\text { (t-Value) }\end{array}$ & $\begin{array}{c}\text { Coefficient } \\
\text { (t-Value) }\end{array}$ \\
\hline $\operatorname{lnSup}$ & $\begin{array}{c}.059 \\
(0.651)\end{array}$ & $\begin{array}{c}-.013 \\
(0.774)\end{array}$ & $\begin{array}{c}.072 \\
(0.230)\end{array}$ \\
\hline lnTemp_moy & $\begin{array}{c}4.627 * * \\
(0.028)\end{array}$ & $\begin{array}{c}.8422 \\
(0.304)\end{array}$ & $\begin{array}{l}2.462 * \\
(0.083)\end{array}$ \\
\hline lnTemp_sq & $\begin{array}{c}-.078 * * \\
(0.032)\end{array}$ & $\begin{array}{c}.042 \\
(0.324)\end{array}$ & $\begin{array}{c}-.042 * * \\
(0.089)\end{array}$ \\
\hline lnPrec_moy & $\begin{array}{c}.433 * \\
(0.057)\end{array}$ & $\begin{array}{c}2.165 * * \\
(0.029)\end{array}$ & $\begin{array}{l}0.137 * \\
(0.095)\end{array}$ \\
\hline lnPrec_sq & $\begin{array}{c}.043 \\
(0.657)\end{array}$ & $\begin{array}{c}-.036 \\
(0.033)\end{array}$ & $\begin{array}{c}1.0795 * \\
(0.056)\end{array}$ \\
\hline $\operatorname{lnTemp} *$ Prec & $\begin{array}{l}-.056 \\
(0.973)\end{array}$ & $\begin{array}{c}* .013 \\
(0.094)\end{array}$ & $\begin{array}{c}-.0023 * * \\
(0.033)\end{array}$ \\
\hline $\operatorname{lnCVT}$ & $\begin{array}{c}-2.473 \\
(0.334)\end{array}$ & $\begin{array}{c}1.385 \\
(0.535)\end{array}$ & $\begin{array}{c}-3.858 * \\
(0.054)\end{array}$ \\
\hline $\operatorname{lnCVP}$ & $\begin{array}{c}.0654 \\
(0.768)\end{array}$ & $\begin{array}{c}.081 \\
(0.617)\end{array}$ & $\begin{array}{c}-.015 \\
(0.920)\end{array}$ \\
\hline Sech & $\begin{array}{l}-.228 * \\
(0.080)\end{array}$ & $\begin{array}{c}-.249 * * * \\
(0.004)\end{array}$ & $\begin{array}{c}.022 \\
(0.831)\end{array}$ \\
\hline Flood & $\begin{array}{c}-.285 \\
(0.113)\end{array}$ & $\begin{array}{c}-.256 \\
(0.012)\end{array}$ & $\begin{array}{c}.028 \\
(0.785)\end{array}$ \\
\hline
\end{tabular}

\section{Source : Author's calculation}

Associated probability in parentheses 
$* \mathrm{p}<0.10, * * \mathrm{p}<0.05, * * * \mathrm{p}<0.01$

The direct effect of temperature is positive, but it did not pass the significance test, indicating that the positive effect of temperature on millet yield in the area is not obvious. The indirect and the total effects of temperature are significantly positive. The increase in temperature will significantly increase millet yield in adjacent (near) areas, and subsequently increase millet yield in all five study areas.

The direct, indirect and total effects of the rainfall variable are significantly positive. Increased rainfall will increase millet yields in the region $i$ by 2.165 percentage points, increases the millet yield in adjacent (nearby) regions by 2.165 percentage points $i$ by 0.137 percentage points and then increases millet yields in all regions by 0.433 percentage point.

Droughts had a direct and total negative impact on millet yield. This is all the more true as the problem of drought is a well-known phenomenon in the study areas and in all regions of Mali. After the major droughts of 1973/74, the government of Mali reacted and tried to integrate this threat into daily life as if it was now part of Malian life and not to see it as an external risk factor (Clot and all, 2008).

From these estimates we see the somewhat surprising result that taking into account the direct positive effect of the interaction between temperature and rainfall as well as the indirect negative effect leads to a total effect that is not significantly different from zero. This means that increasing the interaction between temperature and rain for all regions would probably not have a significant total effect on millet yield over the region $i$.

\section{Conclusion and policy implications}

This article assessed the impacts of climate change on the yield of staple food crops with a focus on maize and millet. It was therefore a question of evaluating the total, direct and indirect effects of precipitation and temperature, floods, droughts and the coefficients of variation of temperatures and precipitation on maize and millet yields through modeling in spatial panel to take into account in a more efficient and finer way the spatial effects, the individual and temporal effects of spatial autocorrelation. To do this, we used panel data from five regions of Mali (excluding the northern regions of Mali: Timbuktu, Gao, Kidal, Ménaka and Taoudéni) during the period 1988 to 2017.

Pesaran's (2006) cross-sectional dependency test was carried out even before comparing spatial panel models in order to take into account the spatial interactions that may exist between regional units. We thus found a transversal dependency between regions. We test spatial models (spatial autoregressive models (SAR), spatial error models (SEM) and spatial durbin models (SDM) using the Wald and LR tests that capture spatial effects. These tests guide us in selecting the appropriate specification and the one that appears to be best suited to our data. Thus, the most appropriate and consistent was the SDM (Spatial Durbin Model) among the spatial panel data models provided for interpretation.

We then estimate our SDM model by looking at spatial spillovers (the effects of changes in independent variables on the dependent variable). As suggested by Pace and Le Sage (2006), the effects of the independent variables were divided into total, indirect (spatial spillover effects) and direct effects in order to improve the identification of the actual impacts and spatial interactions of the factor components on the average yield of maize and millet.

Following the regression results, it can be seen that the average total impacts of temperature and seasonal average rainfall have positive and significant effects on average maize yield and millet yield, while the interaction between temperature and rainfall have negative and significant effects on average maize yield, and droughts are negatively and significantly correlated with millet yield at the $10 \%$ threshold.

Average direct impacts, temperature and seasonal average rainfall have direct positive and significant effects on maize yield, while the area planted and the interaction between temperature and rainfall have direct negative and significant effects on maize yield. In other words, a $1 \%$ increase in temperature and rainfall over the region $i$ leads respectively to a positive variation of $4.84 \%$ and $0.20 \%$ on the yield of maize in our 
region. $i$. However, the direct effect of temperature is positive, but it did not pass the test of significance, indicating that the positive effect of temperature on millet yield in the region is not obvious.

The average indirect impacts, temperature has positive effects on maize yield in the neighboring region. In other words, a $1 \%$ increase in temperature leads to a positive $4.2 \%$ change in maize yield in the neighboring region. However, the effect of rainfall is negative and significant at the $1 \%$ threshold. In other words, a $1 \%$ increase in rainfall would decrease maize yield in neighboring regions by $0.03 \%$. In addition, the direct, indirect and total effects of the precipitation variable are significantly positive. Increased rainfall will increase millet yields in the region. $i$ by 2.165 percentage points, increases the millet yield in adjacent (nearby) regions by 2.165 percentage points. $i$ by 0.137 percentage points and then increases millet yields in all regions by 0.433 percentage points. Second, the droughts had a direct and total negative impact on millet yield.

Overall, our results indicate that when assessing the impacts of climate change on food crop yields (maize and millet) in Mali, policy makers need to take into account that conditions in surrounding areas can influence food crop yields and that the effects of spillover effects differ between crop types.

From a political point of view, two main recommendations can be made. On the one hand, the use of tolerant seeds should be promoted in order to reduce the expected adverse effects of climate change and climate variability. On the other hand, the adoption of any policy to improve maize or millet production in regions with rainfall deficits or high temperature rises must not only take into consideration the amount of water available in the dams and water tables of region $i$, but also integrate all regions neighboring region $i$ in a collective manner depending on the region.

\section{Acknowledgments}

The author would like to thank Mamadou Abdoulaye Konté, Associate Professor of the Faculties of Economics at the University of Gaston Berger of Saint-Louis (Senegal) and Doctor Sokona Dagnoko, Country Director of SASAKAWA AFRICA ASSOCIATION, for their valuable contribution to the creation of this paper.

\section{References:}

[1] Adams R.M., Rosenweig C., Pearl R., Ritchie J., Mc Carl B., Glyer D., Curry B., James J., Boote K., et Allen H., 1990. "Global Climate Change and U.S Agriculture", Nature, 345, pp 219223. http://www.nature.com/nature/journal/v345/n6272/pdf/345219a0.pdf

[2] Anselin, L., J. Le Gallo and H. Jayet, 2008, Spatial panel econometrics. Ch. 19 in L. Mátyás and P. Sevestre, eds., The Econometrics of Panel Data: Fundamentals and Recent Developments in Theory and Practice, Springer-Verlag, Berlin, 625-660.

[3] Baltagi BH (2005). Econometric analysis of panel data, 3rd edn. Wiley, Chichester. https://himayatullah.weebly.com/uploads/5/3/4/0/53400977/baltagi-econometric-analysis-of-paneldata_himmy.pdf

[4] Bassu, S., Brisson, N., Durand, J.-L., Boote, K., Lizaso, J., Jones, J. W., Rosenzweig, C., Ruane, A. C., Adam, M., Baron, C., et al. (2014). How do various maize crop models vary in their responses to climate change factors? Global change biology, 20(7):2301-2320.

[5] Baum C.F., Christopher F. 2006. An introduction to modern econometrics using stata. STATA press, 4905 Lakeway Drive, College station, Texas 77845. ISBN-10: 1-59718-013-0. ISBN-13: 9781-59718-013-9. [Google Scholar]

[6] Blanc. 2012. "The Impact of Climate Change on Crop Yields in Sub-Saharan Africa." American Journal of Climate Change 1 (1): 1-13. https://globalchange.mit.edu/publication/16024

[7] Butt, TA, McCarl, BA, Angerer, J., Dyke, PT, and Stuth, JW. 2005. The economic and food security implications of climate change in Ma li. Climatic change, 68 (3): 355- 378.

[8] Chaisemartin, AM Normann, and J. Pestiaux. 2010. "Extreme climate conditions: How Africa can adapt”. McKinsey's journal. June 2010. 
https://www.mckinsey.com/business-functions/sustainability/our-insights/extreme-climateconditions-how-africa-can-adapt. Accessed April 04, 2020

[9] Chauvin, N. D., F. Mulangu, and G. Porto. 2012. Food production and consumption trends in subSaharan Africa: Prospects for the transformation of the agricultural sector. UNDP Working Paper2012-11. United Nations Development Programme, Regional Bureau for Africa. Addis Ababa, Ethiopia. [Google Scholar]

[10] Clot N, Dacko R.M, Dembelé C, 2008. Changement Climatique au Mali. Introduction et développement du thème Changement Climatique dans la Délégation Inter-coopération Sahel. https://www.iisd.org/cristaltool/documents/intercooperation_changement_climatique_mali.pdf

[11] De Hoyos, R.E and Sarafidis, V. 2006. Testing for cross - sectional dependence in panel data models. The Stata Journal, 6, 482-496.

[12] Direction National de la Météorologie (2016). Plan d'actions national pour la mise en place du cadre national pour les services climatiques au Mali.

[13] Elhorst JP (2014a). Spatial Econometrics From Cross-Sectional Data Spatial Panel. Springer, Heidelberg. Google Scholar. https: //www.springer.com/series/10096

[14] Elhorst, J Paul (2010). « Applied spatial econometrics: raising the bar ». Spatial Economic Analysis 5.1, p. 9-28.

Fotheringham A S and Rogerson PA 2009. Sage's Handbook of Spatial Analysis (London: sage)

[15] Gelfand AE, Diggle P., Guttorp P., Fuentes M, 2010. Handbook of Spatial Statistics. CRC press

[16] Guliyev H, 2020. Determining the spatial effects of COVID-19 using the spatial panel data

[17] model. https://doi.org/10.1016/j.spasta.2020.100443

[18] HARRIS, Richard, John MOFFAT and Victoria KRAVTSOVA (2011). « In search of W ». Spatial Economic Analysis 6.3, p. 249-270.

[19] IPCC. 2013. Climate Change 2013: The Physical Science Basis. Working Group I Contribution to the Fifth Assessment Report of the Intergovernmental Panel on Climate Change. Stocker TF, Qin D., Plattner G.-K., Tignor M., Allen SK, Boschung J., Nauels A., Xia Y., Bex V., Midgley PM (eds.), Cambridge University Press, Cambridge, United Kingdom and New York, NY, USA, 1535 pp . https://www.ipcc.ch/site/assets/uploads/2018/02/WG1AR5_all_final.pdf

[20] Kaiser HM, Riha SJ, Wilks DS, Rossiter DG, and Sampath R., 1993. “ A farm-level analysis of economic and agronomic impacts of gradual warning ", American Journal of Agricultural Economics, 20, pp 387-398.

[21] Kane, S., Reilly, J. and Tobey, J. (1991). Climate Change: Economic implications for world Agriculture. Journal of Agricultural and Resource Economics, 17(1): 195-204. Copyright 1992 Western Agricultural Economics Association.

[22] Le Gallo J. (2002). Econométrie spatiale : l'autocorrélation spatiale dans les modèles de régression linéaire, Economie \& prévision, 4, p. 139-157.

[23] Le Sage, J. P., and Pace, R. K. (2009): Introduction to Spatial Econometrics, CRC Press, Boca Ratón.

[24] MANSKI, Charles F (1993). «Identification of Endogenous Social Effects: The Reflection Problem ». Review of Economic Studies 60.3, p. 531-542.

[25] Mendelsohn, R. Nordhaus, W. \& Shaw, D. (1994).The impact of global warming on agriculture: A Ricardian analysis. American Economic Review 84, 753-771.

[26] MINISTERE DE L'ENVIRONNEMENT, DE L'ASSAINISSEMENT ET DU DEVELOPPEMENT DURABLE (MEADD), 2018. Rapport de la troisième communication nationale du mali à la convention cadre des nations unies sur les changements climatiques. P.121

[27] Nelson, G. C. et al. 2009. Climate change impact on agriculture and costs of adaptation. Washington, DC: International Food Policy Research Institute.

[28] Pesaran MH 2004. "General diagnostic tests for cross section dependence in panels". http://ftp.iza.org/dp1240.pdf

[29] Reilly, J., Hohmann N., and Kane S. 1994. "Climate Change and Agricultural Trade: Who Benefits, Who Loses?’? Global Environmental Change 4, no. 1: 24-36. 
[30] Rosenzweig. C., Iglesias, A., 1994. Implications of Climate Change for International Agriculture: Crop Modeling Study. US Environmental Protection Agency. Washington, DC

[31] Rosenzweig C., and Parry M.L., 1994. "Potential impact of climate change on world food supply", Nature, 367, pp 133-138.

[32] ROUDIER (P.), 2012. Climat et agriculture en Afrique de l'Ouest : Quantification de l'impact du changement climatique sur les rendements et évaluation de l'utilité des prévisions. https://tel.archives-ouvertes.fr/tel-00874724.

[33] Saputro D R S, Muhsinin R Y, Widyaningsih P and Sulistyaningsih. 2019. Spatial autoregressive with a spatial autoregressive error term model and its parameter estimation with two-stage generalized spatial least square procedure. https://doi.org/10.1088/1742-6596/1217/1/012104.

[34] SISSOKO K, SAVADOGO K, VAKSMANN M and TIEMTORE A, 2018. Cereal crops choices and economic resilience face to climate variability in southern Mali. http://publications.cirad.fr/une_notice.php?dk=590004

[35] Wilkinson Emily, Peters Katie, Tanner Thomas, Simonet Catherine, Pichon Florence, Blane Harvey. 2015. Climate extremes and resilient poverty reduction. https://www.odi.org/publications/9609-climate-extremes-and-resilient-poverty-reduction

[36] Yang, W., Chen, BY, Cao, X., Li, T. and Li, P., 2017. The spatial characteristics and influencing factors of modal accessibility gaps: A case study f or Guangzhou, China. 60, 21-32. 